ISSN 1817-3721, E-ISSN 1818-8745

Plant Tissue Cult. \& Biotech. 28(2): 183-190, 2018 (December)

CBangladesh Assoc. for Plant Tissue Culture \& Biotechnology

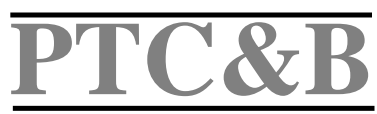

\title{
In vitro Micropropagation and Antioxidant Assay in Colocasia esculenta
}

\author{
M.D. Akshatha, Smitha Kavadikeri ${ }^{1}$ and Nagashree N. Rao ${ }^{1 *}$ \\ Department of Biotechnology, NMKRV College for Women, Bengaluru, India
}

Key words: Colocasia esculenta, Micropropagation, Dedifferentiation, Antioxidant activity

\begin{abstract}
The present work was intended to establish an efficient and reproducible direct regeneration protocol in Colocasia esculenta and to compare the levels of total phenolics and free radical scavenging activity in in vitro regenerated and wild type plants. In vitro micropropogation protocol of the C. esculenta plant was optimized using meristem as explant. The surface sterilized explants were inoculated on MS supplemented with varied concentration and combination of auxin and cytokinins. The cultures were maintained at $26^{\circ} \mathrm{C}$ under a $12 \mathrm{hrs}$ photoperiod. Total phenolic content and free radical scavenging assay was carried out in wild type plants and compared with in vitro micropropagated plants using DPPH method. Statistical analysis of the data was carried out using STATISTICA 13 software. An efficient in vitro micropropagation protocol was established for C. esculenta. Antioxidant activity and total phenolic content was marginally increased in tissue cultured plants compared to wild type plants of $C$. esculenta.
\end{abstract}

\section{Introduction}

Plants are being used as drug since the time immemorial. Plant based medicine has been extensively used to recognize and embolden the development of modern medicines and drugs. Plants produce diverse bioactive compounds or natural products that are synthesized as a product of secondary metabolism. Many medicinal plants have become source of new lead molecules in therapeutics (Umesh 2014). Colocasia esculenta a perennial herb commonly called as Taro belongs to Araceae. It is an invasive wetland plant native to southern Asia and Indian sub-continent. Taro corm and leaves are used in various food

*Author for correspondence: <nagashrreenrao@gmail.com>. 'Department of Biotechnology, RV College of Engineering, Bengaluru, India.

DOI: https://doi.org/10.3329/ptcb.v28i2.39677 
preparations (Chanda et al. 2013). The herb has been known to be utilized for treatment of various health problems such as asthma, arthritis, diarrhea, internal hemorrhage, neurological disorders and skin disorders. This is one of the useful medicinal plants described by Charaka as anti-inflammatory plant (Kubde et al. 2010). Carbohydrates in C. esculenta corms shows excellent digestibility and hence can be consumed by people who are allergic to cereals and baby foods for babies with lactose intolerance (Lee 1999, Darkwa and Darkwa 2013). Taro silage is used as animal feed and in cosmetic industry, plastic manufacturing and alcohol production (Griffin 1982).

In C. esculanta, the cormels are normally used for vegetative propagation. In C. esculenta under normal field condition, survival of the emerged plantlets after detaching from mother plant is at stake as the multiple shoot produces a few adventitious roots. The corms upon harvesting are sensitive to cold temperature hence are maintained at ambient temperature. During May to August due to high temperature and high humidity the cormels will start germination after the transient dormancy period. But upon storage germination potential will be lost. Hence conventional maintenance of germplasm of this crop is cumbersome (Hossain 2012). In vitro tissue culture approach would be a substitute for mass multiplication and to conserve the germplasm of Colocasia esculenta. A few reports in C. esculenta are available on its antioxidant properties (Sheik 2016, Yadav et al. 2017). In the present study an efficient and reproducible protocol for mass production of $C$. esculanta was optimized and a comparative study between the in vitro regenerated plant and wild type plants was carried out to analyse the levels of total phenolic content and antioxidant potential.

\section{Materials and Methods}

The corms of Colocasia esculenta var. Sreekiran was collected from Central Tuber Crop Research Institute, Thiruvanthapuram, Kerala, India. The germplasm is being maintained in the greenhouse at R.V. College of Engineering, Bengaluru, India.

The corms were treated with $1 \%$ gibberellic acid $\left(\mathrm{GA}_{3}\right)$, to break dormancy of the axillary buds. The corms were moistened with $1 \% \mathrm{GA}_{3}$ and exposed to sunlight. After a week of the incubation the sprouted axillary buds were excised and used as explant. The axillary buds were washed thoroughly with running tap water followed by washes in Tween 20 and $0.1 \%$ cetrimide for ten minutes each. Later the explants were rinsed with $70 \%$ alcohol for $10 \mathrm{~min}$. and again treated with $2 \%$ Bavistin and $0.25 \%$ Cefotaxime with agitation for 2 hrs. The explants were further treated with $10 \%$ hydrogen peroxide for ten minutes and washed thoroughly with sterile distilled water. For clonal propagation meristem 
of the plant was used as explant. For callusing, leaves, leaf midrib and axillary buds were also used as explants.

The surface sterilized explants were inoculated on modified MS basal medium supplemented with glutamine as adjuvant and different combinations and concentration of 2,4-D and NAA and TDZ, BAP, Kn, glutamine along with $0.5 \%$ activated charcoal (Table 1). The cultures were incubated at $26 \pm 2^{0} \mathrm{C}$ under $16 / 8 \mathrm{hrs}$ photoperiod for 3 weeks. After 10 days of incubation, the in vitro shoots were sub-cultured and incubated for 30 days for the elongation and rooting of the shoots. The well-established rooted in vitro plantlets were hardened in soilrite for 15 days then the plantlets were acclimatized in vermiculite and soil mixture for 7 days (Nath et al. 2012). The well-established micropropogated plants were transferred to soil and maintained in greenhouse.

Preparation of plant extracts for estimating total phenolic content and antioxidant activity: Leaves and corm of wild type and in vitro regenerated plants were shade dried and powdered in a blender. $30 \mathrm{~g}$ of the powdered sample was extracted in methanol and using soxhlet apparatus at $55^{\circ} \mathrm{C}$ for 35 cycles. The extract was condensed to powder at room temperature. The residue was suspended in $10 \mathrm{ml}$ of methanol and the methanolic extract was used for further analysis.

The stable DPPH radical was used for determination of free radicalscavenging activity of the plant extracts. One $\mathrm{ml}$ of $0.1 \mathrm{mM}$ freshly prepared solution of DPPH in methanol was mixed with $3 \mathrm{ml}$ of plant extract in methanol (25 - $400 \mu \mathrm{g} / \mathrm{ml}$ ) and mixed well and incubated in dark for $30 \mathrm{~min}$. The absorbance was recorded at $517 \mathrm{~nm}$ against ascorbic acid as reference. The percentage of inhibition activity was calculated using:

Inhibition $(\%)=[(\mathrm{A} 0-\mathrm{A} 1) / \mathrm{A} 0]^{*} 100$

A0 - Absorbance of control, A1 - Absorbance of sample (Shen et al. 2010).

All tests were performed in triplicate and the graph was plotted with the average of the three determinations. An IC50 was calculated as the concentration which brought about a 50\% reduction in absorbance compared to blank (Sharma et al. 2014).

The total phenolic content of all extracts were measured at $765 \mathrm{~nm}$ by $1: 10$ diluted Folin-Ciocalteu (FC) reagent (Eugino et al. 2017). $0.5 \mathrm{ml}$ of plant extracts (1 $\mathrm{mg} / \mathrm{ml}$ stock) was mixed with $5 \mathrm{ml} \mathrm{FC}$ reagent and $4 \mathrm{ml}$ of $1 \mathrm{M}$ aqueous sodium carbonate. The mixture was allowed to stand for $30 \mathrm{~min}$ and the total phenolic content of all the samples were determined by spectrophotometer at 765 $\mathrm{nm}$. The standard curve was prepared using gallic acid in methanol : water (50: $50, \mathrm{v} / \mathrm{N})$. Total phenol values were expressed in terms of gallic acid equivalent 
(mg/gm of dry mass), all tests were performed in triplicate and the graph was plotted with the average of the three determinations.

Micropropagation experiments were repeated three times and ten explants per one treatment were used per each growth regulator concentration and each type of explants. Plantlet acclimatization experiments were also carried out in triplicate. The results were expressed as mean values $\pm \mathrm{Sd}$. Data were analysed by Tukeys HSD test at the $\leq 0.05$ significance level using STATISTICA 13 software.

\section{Results and Discussion}

Standardization of the surface sterilization for Colocasia esculenta was a challenge in combating the endophytic organisms present in the corms. Earlier reports have shown the presence of endogenous microorganisms which includes Methylobacterium mesophilicum and Pseudomonas fluorescence (Taylor, 1994). However, after following stringent surface sterilization method $85 \%$ sterile explants were rescued.

The explants were inoculated on MS supplemented with auxin and cytokinins and incubated in both dark and light conditions at $26 \pm 2^{\circ} \mathrm{C}$. The plant cultures incubated in dark did not respond and the explants were completely bleached within a week. Hence, all the cultures were incubated and maintained under light conditions.

The axillary buds were inoculated on MS containing cytokinin alone for shoot elongation and combination of auxin and cytokinins were used for the regeneration of explants. Among the different combinations of plant regulators the MS medium containing 2,4-D (2 mg 1$)$, TDZ ( $1 \mathrm{mg} \Lambda)$ along with $0.5 \%$ activated charcoal and $800 \mathrm{mg} /$ of glutamine, the shoot elongation started in meristem explants by fortnight and root initiation by 5 weeks of incubation. The regeneration potential for this combination of medium was up to $85 \%$ (Fig. 1). However, medium augmented with $2 \mathrm{mg} / \mathrm{BAP}$ and $0.5 \mathrm{mg} / \mathrm{NAA}$ also showed shoot elongation after 5 weeks of incubation with low regeneration frequency. Reports of clonal propagation of taro are available and suggesting multiplication of taro in three stages with TDZ and BAP (Tuia et al. 1997). A rapid in vitro regeneration of $C$. esculenta using combination of NAA and BAP and rooting was obtained in basal MS (Nath et al. 2012). In our study, the shoot regeneration with BAP was delayed compared to TDZ and the shoots regenerated with TDZ were longer than the shoots developed on BAP medium.

In DPPH scavenging assay, methanolic extracts of wildtype and micropropagated plants exhibited marked DPPH free radical scavenging activity 
in concentration dependent manner (Table 1). The corm extract shows effective scavenging activity than leaf extract. In vitro grown plants showed slightly higher free radical scavenging activity. The scavenging activity was found to be increase with the increase in the concentration of the extract (Basu et al. 2012). $\mathrm{IC}_{50}$ value for micropropagated plants was found to be $36.8,23.3 \mu \mathrm{g} / \mathrm{ml}$ for greenhouse maintained plant leaf and corm, respectively and 21.2, $21.4 \mu \mathrm{g} / \mathrm{ml}$ for micropropagated leaves and corms, respectively. Plants with $10-50 \mu \mathrm{g} / \mathrm{ml} \mathrm{IC}_{50}$ value has strong antioxidant activity (Phongpaichit et al. 2007). By the results it can be concluded that $C$. esculenta have a strong antioxidant activity which was enhanced due to augmentation of growth regulators in tissue cultured plantlets. Similar results obtained in Excocaria agallocha where in vitro grown plants showed increased free radical scavenging activity (Arumugam et al. 2013).

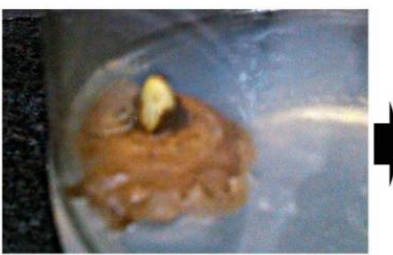

(A)

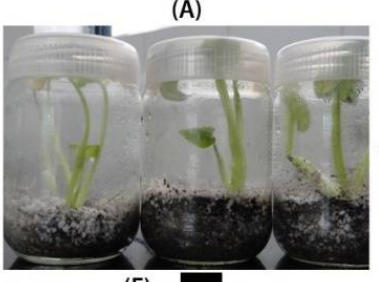

(F)

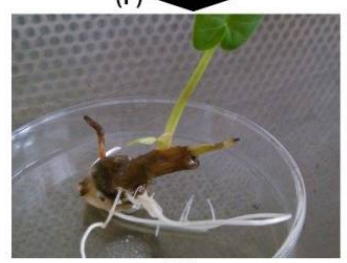

(G)

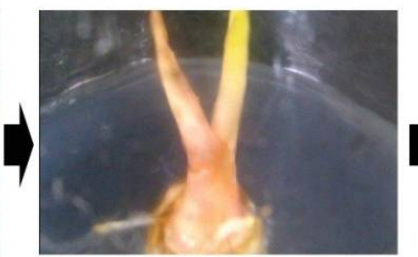

(B)

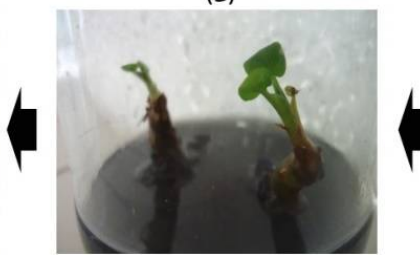

(E)

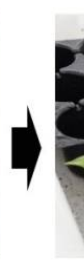

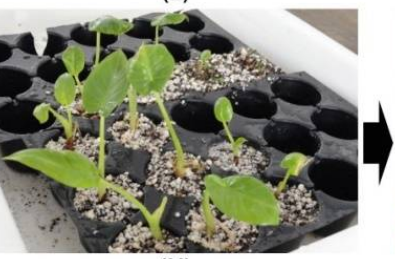

(H)

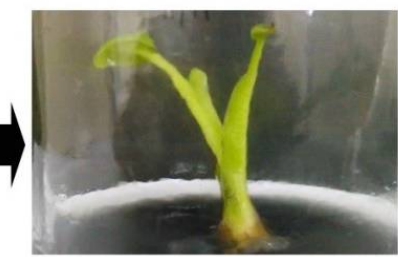

(C)

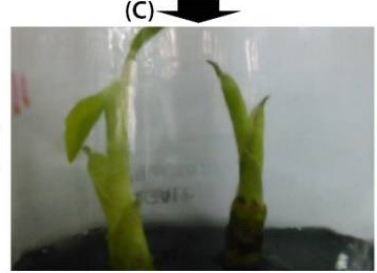

(D)

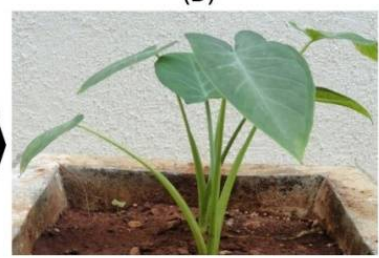

(I)

Fig. 1. Different stages of micropropagation of C. esculenta. (A). Surface sterilized explant was inoculated to MS. (B). Regeneration of explants on the MS. (C,D,E). Different stages of microshoot regeneration on MS medium with $2 \mathrm{mg} /$ 2,4,-D, $1 \mathrm{mg} / \mathrm{TDZ}, 800$ $\mathrm{mg} /$ glutamine and $0.5 \%$ activated charcoal. $(\mathrm{F}, \mathrm{G})$. Initiation of roots in the same medium of microshoot regeneration. (H). Acclimatization of plantlets. (I). Greenhouse maintenance.

The total phenolic estimation from leaves and corms of greenhouse grown plants and in vitro grown plants were $82.2 \pm 1.39$ and $88.1 \pm 2.0 \mathrm{mg} / \mathrm{g}$ and $90.32 \pm$ $1.39,93.5 \pm 1.3 \mathrm{mg} / \mathrm{g}$, respectively. Phenolic compounds have the ability to destroy free radicals because they contain hydroxyl groups. They give up 
hydrogen atoms of their hydroxyl group radicals and form stable phenoxyl radical hence play important role in antioxidant activity. Therefore determination of phenolics quantity is very important in order to determine the antioxidant activity of plant extracts (Das et al. 1990, De Gaulejac 1999). Polyphenols are the most effective antioxidant constituents of plant kingdom and it is important to estimate phenolic contents of plant extracts to justify their antioxidant activity (Sharma et al. 2009). Increased phenolic content in tissue cultured plants have positive correlation with increased phenolic content in plants.

Table 1. Antioxidant assay of methanolic extracts of greenhouse maintained and in vitro micropropagated plants

\begin{tabular}{lccccc}
\hline Plant extract in & Concentration & \multicolumn{4}{c}{ Percentage scavenging } \\
\cline { 3 - 6 } Methanol & $\begin{array}{c}\text { Of the plant } \\
\text { extract }(\mu \mathrm{m})\end{array}$ & $\begin{array}{c}\text { Corm } \\
\text { extract }\end{array}$ & $\begin{array}{c}\mathrm{IC}_{50} \\
\mu \mathrm{g} / \mathrm{ml}\end{array}$ & $\begin{array}{c}\text { Leaf } \\
\text { extract }\end{array}$ & $\mu \mathrm{I} / \mathrm{ml}$ \\
\hline Greenhouse plants & 25 & $32 \pm 1.0^{\mathrm{b}}$ & & $35 \pm 2.1^{\mathrm{a}}$ & \\
& 50 & $47 \pm 0.7^{\mathrm{c}}$ & & $47 \pm 1.7^{\mathrm{b}}$ & \\
& 100 & $79 \pm 1.4^{\mathrm{d}}$ & 23.3 & $78 \pm 1.6^{\mathrm{d}}$ & 36.8 \\
& 200 & $81 \pm 0.7^{\mathrm{e}}$ & & $87 \pm 0.8^{\mathrm{f}}$ & \\
& 400 & $92 \pm 3.5^{\mathrm{e}}$ & & $91 \pm 2.1^{\mathrm{f}}$ & \\
Micropropagated & 25 & $39 \pm 1.2^{\mathrm{a}}$ & & $31 \pm 1.4^{\mathrm{b}}$ & \\
plants & 50 & $45 \pm 1.0^{\mathrm{a}}$ & & $57 \pm 0.9^{\mathrm{d}}$ & \\
& 100 & $78 \pm 2.1^{\mathrm{a}}$ & 21.4 & $72 \pm 1.3^{\mathrm{e}}$ & 21.2 \\
& 200 & $84 \pm 0.6^{\mathrm{b}}$ & & $88 \pm 0.5^{\mathrm{f}}$ & \\
& 400 & $92 \pm 0.7^{\mathrm{c}}$ & & $92 \pm 0.7^{\mathrm{g}}$ & \\
\hline
\end{tabular}

Results are mean of three trials. The values followed by same alphabet do not differ significantly according to Tukey's HSD test at $\leq 0.05 \%$ level of significance.

In plants ascorbic acid-glutathione cycle plays a vital role in free radical scavenging and multiplication in stress conditions. The concentration of ascorbic acid in plants depends on the intensity of stress (Lim et al. 2007). The reason for decreased amount of total phenolics in greenhouse grown plants may be due to drying process. Some phenolic compounds degrade rapidly at certain temperature which may result in loss of naturally occurring antioxidants and phenols. But drying can result in every little change in phenolic content (Tomaino et al. 2005)

The present investigation revealed that the C. esculenta is having strong antioxidant activity. The antioxidant activity increased in micropropagaetd plants. This may be due to stress induced in vitro conditions. 


\section{References}

Arumugam M, Pawar UR and Gomathinayagama M (2012) Antibacterial and antioxidant activity between micropropagated and field grown plants of Excocaria agallocha L. IRJP 3(3).

Basu S, Sen A, Das M, Nath P and Datta G (2012) Phytochemical evaluation and in vitro study of antioxidant potency of Amorphophallus campanulatus, Alocasia indica and Colocasia esculenta : a comparative analysis. Int. J. Pharm. Bio. Sci. 3(3): 170 -180.

Chanda S, Rakholiya K, Dholakia K and Baravallia Y (2013) Antimicrobial, antioxidant, and synergistic properties of two nutraceutical plants: Terminalia catappa and Colocasia esculenta L. Turkish. J. Biol. 37: 81-91.

Darkwa S and Darkwa A (2013) Taro Colocasia esculenta. Its utilization in food products in Ghana. J. Food Process Technol. 4: 225.

Das NP and Pereira TA (1990) Effects of flavonoids on thermal auto oxidation of palm oil : structure-activity relationship. J. Amer. Oil Chem. Soc. 67: 255-258.

De Gaulejac NSC, Glories Y and Vivas N (1999) Free radical scavenging effect of anthocyanins in red wines. Food Res. Int. 32: 327-333.

Eugino MHA, Periera RGFA, Abreu WC and Periera MCA (2017) Phenolic compounds and antioxidant activity of tuberous root leaves. Int. J. Food Prop. 20(12): 2966-2973.

Griffin GJL (1982) Potential applications of taro starch. Paper presented at the Regional Meeting on Edible Aroids, Suva, Fiji.

Hossain MJ (2012) In vitro organogenesis of Colocasia esculanta cv. antiquorum L. Am J. Plant Sci. 3: 709-713.

Kubde SM, Khadabadi SS, Saboo SS, Gorpade DS and Modi AJ (2010) In vitro antimicrobial activity of crude extract of Colocasia esculenta leaves. IJPSR. 1(8): 88-91.

Lee W (1999) Taro (Colocasia esculenta), Ethnobotanical Leaflets 1999(1).

Lim YY and Murtijaya J (2007) Anti-oxidant properties of Phyllanthus amarus extracts affected by different drying methods. LWT- Food Sci. Technol. 40: 1664-1669.

Nath VS, Senthil M, Hegde VM, Jeeva ML, Misra R and Veena SS (2012) A simple and efficient protocol for rapid regeneration and propagation of taro (Colocasia esculenta L. Schott.) in vitro using apical meristem. IJPD 6(1): 64-66.

Phongpaichit S, Nikom J, Rungjindamai, Sakayaroj N, Hutadiolk, Towatana, Rukachaisirikul V and Kirtikara K (2007) Biological activities of extracts from endophytic fungi isolated from Garcinia plants. FEMS Immunol. Med. Microbiol. 51(3): 517-525.

Sharma I, Manisha M, Singh GP and Anirudha R (2014) Quantitave estimation of phenolic and flavonoid content and antioxidant activity of various extracts of different parts of Plumbago zeylanica Linn. Int. J. Drug Dev. Res. 6(2): 136-140.

Sharma OP and Bhat TK (2009) DPPH: antioxidant assay revisited. Food Chem. 113: 1202-1205.

Sheikh MA and Tembhre M (2016) Preliminary phytochemical screening, in vitro antioxidant activity, total phenolics, total flavonoid content of C. esculenta leaf extract. Asian. J. Exp. Sci. 30(1\&2): 39-43.

Shen Q, Zhang B, Xu R, Wang Y, Ding and Li P (2010) Antioxidant activity in vitro of the selenium-contained protein from the Se-enriched Bifidobacterium animalis. Anaerobe $\mathbf{1 6}$. 380-386. 
Taylor MB (1994) Tissue culture of taro Colocasia esculenta var. esculenta. PRAP 1994: 1

Tomaino A, Cimino F, Zimbalatti V, Venuti V, Sulfaro V and De Pascale A (2005) Influence of heating on antioxidant activity and the chemical composition of some spice essential oils. Food Chem. 89: 549-554.

Tuia VS (1997) In vitro multiplication of taro (Colocasia esculenta var. esiculenta L. Schott), M. Agri. University of the South Pacific.

Umesh TG (2014) In vitro callus induction and antioxidant potential of Decalepis hamiltonii (wight and arn). Int. J. Pharm. Sci. 6(6): 452-456.

Yadav M, Kushawaha DK, Chatterji S and Watal G (2017) Assessment of antioxidant activity and phytochemical screening of C. esculenta. IJPSR 32: 8(4): 1758-1764.

Yam TW, John L, Young P, Kap P, Fan L and Arditti J (1990) Induction of callus from axillary buds of taro (Colocasia esculenta var. esculenta, Araceae) and subsequent plantlet regeneration. Plant Cell Rep. 9: 459-462. 